\title{
Overview of a Proposed Flight Validation of Aerocapture System Technology for Plan'etary Missions
}

\author{
Andrew S. Keys* \\ NASA Marshall Space Flight Center, Huntsville, AL 35812 \\ Jeffery L. Hall ${ }^{\dagger}$ and David $\mathrm{Oh}^{\ddagger}$ \\ Jet Propulsion Laboratory, California Institute of Technology, Pasadena, CA 91109 \\ and \\ Michelle M. Munk ${ }^{8}$ \\ NASA Langley Research Center, Hampton, VA 23681
}

\begin{abstract}
Aerocapture System Technology for Planetary Missions is being proposed to NASA's New Millennium Program for flight aboard the Space Technology 9 (ST9) flight opportunity. The proposed ST9 aerocapture mission is a system-level flight validation of the aerocapture maneuver as performed by an instrumented, high-fidelity flight vehicle within a true in-space and atmospheric environment. Successful validation of the aerocapture maneuver will be enabled through the flight validation of an advanced guidance, navigation, and control system as developed by Ball Aerospace and two advanced Thermal Protection System (TPS) materials, Silicon Refined Ablative Material-20 (SRAM-20) and SRAM-14, as developed by Applied Research Associates (ARA) Ablatives Laboratory. The ST9 aerocapture flight validation will be sufficient for immediate infusion of these technologies into NASA science missions being proposed for flight to a variety of Solar System destinations possessing a significant planetary atmosphere.
\end{abstract}

\section{Nomenclature}

$\Delta V=$ relative velocity change

\section{- I. Introduction}

$\mathrm{I}^{\mathrm{N}}$ N late 2006, NASA's New Millennium Program (NMP) will select a proposed advanced technology to be incorporated into its Space Technology-9 (ST9) system-level flight validation experiment, currently slated for launch in 2010. The goal of the NMP is to flight validate innovative, enabling, breakthrough technologies such that the risk and cost of first flight usage is minimized for the benefit of use on future space science and exploration missions. Aerocapture System Technology for Planetary Missions (hereafter referred to as aerocapture) is one of five candidate system-level technologies being proposed to the NMP for in-space validation aboard the ST9 flight opportunity. All five proposed technologies are currently in a Phase A formulation stage of development. They each will culminate their formulation activity with the submittal of a Concept Definition Study Report (CDSR). The CDSR describes a proposed system-level technology validation mission for flight aboard the ST9 opportunity and is the basis upon which the NMP will select one of the five competing technologies.

The aerocapture mission being proposed for ST9 is a low complexity, short duration mission that will flight validate the execution of an aerocapture maneuver. If selected to fly aboard the ST9 opportunity, a successful flight validation of the aerocapture maneuver provides risk reduction and technology value to future NASA science missions destined to Solar System bodies possessing significant atmospheres. Missions to explore Saturn's moon

\footnotetext{
* ST9 Aeroshell Subsystem Manager, NASA MSFC

† ST9 Aerocapture Project Lead, NASA JPL, AIAA Senior Member

‡ ST9 Aerocapture Chief Engineer, NASA JPL

${ }^{\S}$ ST9 Aerocapture Chief Technologist, NASA LaRC
} 
Titan and other science orbiters to Mars and Venus would all realize a launched mass benefit from the use of an aerocapture maneuver. Corollary applications for other missions requiring atmospheric re-entry and precision landing would also realize benefit from an aerocapture flight validation in the form of improved aero/aerothermodynamic model validation, hypersonic flight guidance system validation, advanced Thermal Protection System (TPS) material validation, and performance model validation.

\section{Aerocapture System Technology Description}

Exploration of the Solar System favors the use of a high velocity transit across the vast distances between Earth and any target destination. Upon arrival at a destination, missions requiring the establishment of a stable working orbit must reduce the acquired high transit velocity such that the final orbit is attained. The conventional approach to decelerating the spacecraft by a specific amount of relative velocity required to establish an orbit, defined as $\Delta V$, relies on the firing of the spacecraft's propulsion system. This approach consumes a large fraction of the spacecrafts launch mass in the form of spent propellant and is thus considered inefficient in terms of the effective payload-tolaunched mass ratio. Aerocapture addresses this inefficiency and provides an attractive alternative to the allpropulsive method of payload orbital capture and insertion.

The term "aerocapture" refers to a spacecraft flight maneuver executed upon arrival at a planetary destination in which a single atmospheric pass is used to decelerate the spacecraft into a prescribed working orbit. The reduction of velocity through aerodynamic forces allows the gravitational "capture' of the spacecraft into orbit. To successfully perform the aerocapture maneuver, a thermally protected flight vehicle, as exemplified by the aerostructure depicted in Fig. 1, must make an autonomously-guided atmospheric flight that follows a precise flight corridor into, through, and out of a planetary atmosphere. Following the pass, the spacecraft executes one or more in-vacuum propulsive firings to raise the orbital periapsis above the atmosphere and correct for delivery errors.

For the sake of clarity and to avoid confusion, the term 'aerobraking" is defined herein as the process of using hundreds of orbital passes through the thin

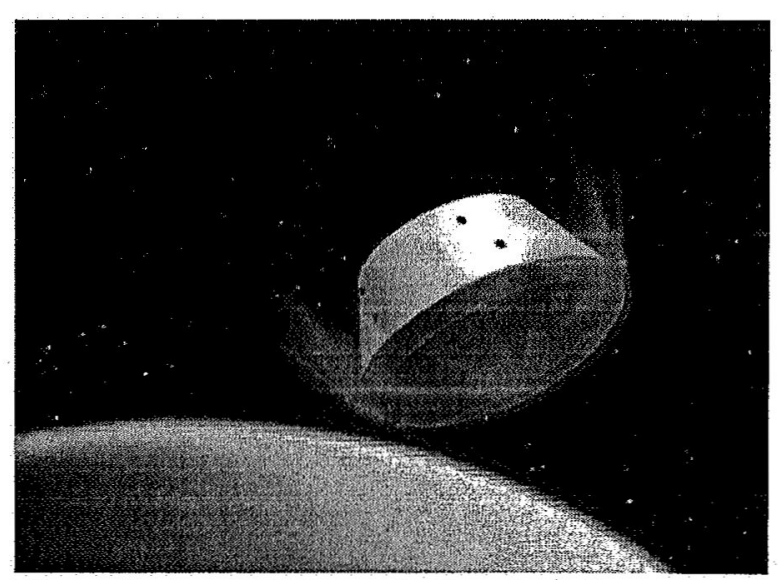

Figure 1. An artist's rendering depicting a bluntbody aerostructure performing an aerocapture maneuver as it navigates through the atmosphere of a planetary body. upper limits of a planets atmosphere to reduce the apoapsis of an already-established initial elliptical orbit - eventually resulting in a more circular final working orbit that is suitable for science operations. Aerobraking does not require significant thermal protection of the spacecraft, but instead requires sufficient propellant to establish the initial elliptical orbit plus additional propellant for aerobraking trajectory targeting. Because aerobraking only grazes the upper limits of an often dynamic planetary atmosphere, the process of implementing this orbital maneuver is operationally intensive and time consuming, often taking months to evolve a highly elliptical initial orbit into a tighter, more circular final working orbit.

Once aerocapture is flight validated, it will be a valuable capability that possesses application across a wide range of planetary mission sizes and destinations. Aerocapture can greatly reduce the propellant mass launched and carried by the spacecraft by using a planets atmosphere rather than propellant expenditure to absorb and disperse the spacecrafts kinetic energy. This launched propellant mass savings enables either larger payload mass fractions or smaller launch vehicles from Earth. The propellant mass savings of aerocapture becomes especially significant for missions requiring large velocity changes to achieve orbital insertion, either because a low circular orbit is required or because the approach velocity is high. In some cases, aerocapture not only serves as an efficient method for delivering payload mass, but is an enabling technology without which no payload mass would be delivered at all. Table 1 provides data as derived from a cost-benefit analysis study ${ }^{1}$ performed to address the advantages of aerocapture delivery as compared to competing orbital insertion techniques (including advanced chemical propulsion, solar electric propulsion, and aerobraking). The table identifies example missions where aerocapture not only increases delivered payload mass beyond the next best propulsion technology, but enables the mission as the only propulsion technology capable of attaining the final working orbit. 
Table 1. Aerocapture Mission Benefit Analysis (Derived from Ref. 1)

\begin{tabular}{|l|l|c|c|c|}
\hline Destination & \multicolumn{1}{|c|}{ Working Orbit $(\mathbf{k m})$} & $\begin{array}{c}\text { Nominal Inertial } \\
\text { Entry Speed }(\mathbf{k m} / \mathbf{s})\end{array}$ & $\begin{array}{c}\text { Orbit Insertion, } \\
\Delta V(\mathbf{k m} / \mathbf{s})\end{array}$ & $\begin{array}{c}\text { Delivered Payload } \\
\text { Mass Increase }\end{array}$ \\
\hline Venus & 300 (circular) & 11.7 & 4.6 & $79 \%$ \\
\hline Venus & $8,500 \times 300$ (elliptical) & 11.7 & 3.3 & $43 \%$ \\
\hline Mars & 300 (circular) & 5.9 & 2.4 & $15 \%$ \\
\hline Mars & $37,000 \times 300$ (elliptical) & 5.9 & 1.2 & $5 \%$ \\
\hline Jupiter & 2000 (circular) & 59.0 & 17.0 & Infinite \\
\hline Jupiter & $1,880,000 \times 1,000$ (elliptical) & 59.0 & 1.4 & $-51 \%$ \\
\hline Saturn & 120,000 (circular) & 35.0 & 8.0 & Infinite \\
\hline Titan & 1,700 (circular) & 5.9 & 4.4 & $280 \%$ \\
\hline Uranus & $450,000 \times 4,000$ (elliptical) & 24.0 & 4.5 & $218 \%$ \\
\hline Neptune & $430,000 \times 4,000$ (elliptical) & 29.0 & 6.0 & $832 \%$ \\
\hline
\end{tabular}

In addition to the primary benefit of demonstrating aerocapture as an orbital insertion maneuver, the proposed ST9 aerocapture flight validation experiment will further benefit surface-direct atmospheric entry missions involving surface probes, landers, and rovers by providing flight validation of an active trajectory modulation and flight corridor navigation system as implemented by the spacecrafts onboard autonomous guidance, navigation and control algorithm. The proposed experiment will also flight validate a new TPS material for use on other atmospheric re-entry missions. Additionally, this proposed experiment will be highly instrumented, collecting data needed to validate the performance of computational fluid dynamic (CFD) codes used for aerodynamic and aerothermal environmental assessment and modeling, trajectory codes, and thermal protection system performance codes.

Despite the mass advantage provided through the use of an aerocapture maneuver, this valuable approach to orbital insertion has yet to be employed on any planetary mission. In part, this is because the aerocapture maneuver is a mission critical event which must exhibit a fundamentally low level of acceptable risk. The process required to attain an acceptably low risk level is costly and time consuming. Additionally, to date, NASA has been able to plan achievable mission objectives at remote planetary destinations by accepting the mass penalty associated with orbital insertion using conventional propulsion techniques, making the funding required to reduce aerocapture risk difficult to secure. However, as mission managers devise more complicated and difficult-to-attain science objectives while seeking high efficiency methods of accessing remote Solar System destinations, the justification for a first use aerocapture technology validation flight, such as would be provided by this proposed ST9 aerocapture mission, increases.

\section{ST9 Aerocapture Management Approach}

The recognized value of aerocapture as an enabling capability for Solar System exploration has motivated multiple NASA-funded efforts in recent years to invest in the development, maturation, and ultimate flight of technologies that support a system-level aerocapture capability. In 2004, the NMP released a NASA Research Announcement soliciting for technologies in the areas of guidance algorithms and software, instrumentation, and advanced TPS materials. Several years ago, the Jet Propulsion Laboratory (JPL) proposed an aerocapture flight validation to the NMPS ST7 opportunity ${ }^{2}$. Today, JPL is proposing a system-level aerocapture flight validation to the ST9 opportunity as a partnership between the NMP and the In-Space Propulsion Technology Program.

The In-Space Propulsion Technology Program is managed by NASA's Science Mission Directorate and is implemented by the In-Space Propulsion Technology (ISPT) Project at Marshall Space Flight Center. The objective of the ISPT Project is to mature technologies applicable to space propulsion applications for incorporation into nearterm flight opportunities. Aerocapture is a major portion of the ISPT portfolio ${ }^{3}$ and has been identified by the NMP as being appropriately mature for a flight validation. ISPTs investment in aerocapture technologies has significantly advanced the maturity level of aerocapture-related technologies and argues for mission infusion in reports of studies using aerocapture at various Solar System destinations ${ }^{4-6}$.

The complete ST9 aerocapture proposal effort is led by JPL, but leverages aerocapture technology through a partnership with the ISPT project. As a logical fulfillment to the ISPTs investment in aerocapture technologies, ISPT has partnered with JPL to fund, develop, manage and deliver the ST9 aerocapture flight vehicle's aeroshell subsystem for integration into the rest of the flight vehicle. The ISPT-managed aeroshell consists of the forebody 
heatshield structure, the aftbody backshell structure, the equipment plate, the back interface plate, the closeout panel, the advanced TPS materials on both the heatshield and the backshell, and the integrated instruments located at strategic points about the spacecraft.

\section{Proposed ST9 Aerocapture Mission Profile}

Because of imposed funding ceilings, the proposed ST9 aerocapture flight validation necessitates an Earth orbit flight test rather than a validation within the atmosphere of some other Solar System destination. Ideally, the flight vehicle would approach Earth or some other destination on a hyperbolic trajectory to emulate a true aerocapture maneuver, namely "capturing' the vehicle by using drag to alter the spacecrafts flight path from a hyperbolic trajectory to an elliptical orbit. However, all essential characteristics of aerocapture flight can be sufficiently evaluated without a hyperbolic to elliptic orbit change. Past studies have established that the characteristics of aerocapture flight dynamics and the system effects of navigational, atmospheric, and aerodynamic uncertainties are within the same order of magnitude at Earth as they are at the other studied Solar System destinations. These identified flight dynamic characteristics are: 1) the percentage of $\Delta V$ accomplished with the aerodynamic maneuver, 2) the magnitude of the uncertainties the flight system must accommodate, 3) the aerodynamic and ballistic coefficient characteristics of the vehicle, and 4) the autonomous operation of the integrated flight vehicle and guidance system.

\section{A. Mission Sequence}

The flight vehicle is designed to be launched as a secondary shared payload on a Boeing Delta II launch vehicle using the reduced height dual payload adapter fitting. To maximize its compatibility with other potential satellite customers, the flight plan for the aerocapture flight vehicle begins with insertion into a highly elliptical orbit with an apoapsis tolerance ranging from a minimum of $20,000 \mathrm{~km}$ up to a geosynchonous transfer orbital apoapsis of 36,000 $\mathrm{km}$. The attained apoapsis determines the entry velocity achieved once the flight vehicle re-enters the atmosphere. A minimum entry velocity of $9.5 \mathrm{~km} / \mathrm{s}$ (as attained from the $20,000 \mathrm{~km}$ apogee) is required to properly validate the guidance and control algorithm as it executes the descent arrest, equilibrium glide, and atmospheric exit stages of the aerocapture maneuver. As a result, the flight vehicle mass is constrained to less than $185 \mathrm{~kg}$ based on the Delta IIs ability to launch the payload to the minimum required apogee of $20,000 \mathrm{~km}$.

The proposed ST9 Aerocapture mission is schematically depicted in Fig. 2. Once launch occurs and the flight

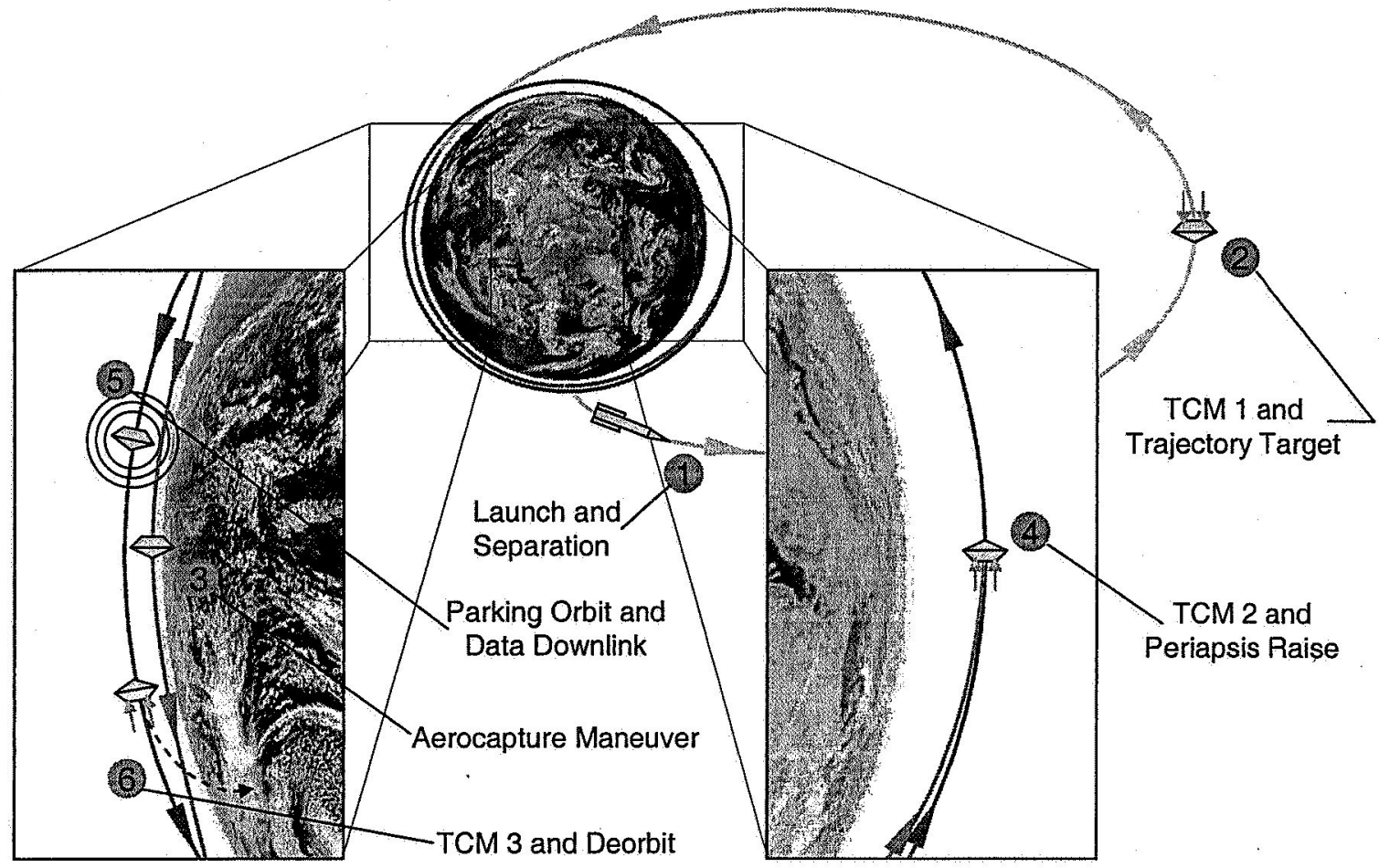

Figure 2. Simplified schematic of the proposed mission profile for ST9 Aerocapture. 
vehicle separates from the launch vehicle and launch adapter, it initializes navigational systems and enters a cruise mode to attain the required apogee, occurring approximately 2.5 hours after launch. The first of three trajectory control maneuvers (TCMs) executes near orbital apoapsis and targets, the flight vehicle for a precise entry into the necessary flight path corridor required to properly execute the aerocapture maneuver. The maneuver itself begins with atmospheric entry at an attained velocity of greater than $9.5 \mathrm{~km} / \mathrm{s}$. The onboard guidance system provides autonomous control of the flight vehicle to arrest the vehicle's descent, perform an equilibrium glide at hypersonic speeds through an increasingly narrow flight corridor, and then exit the atmosphere. During the aerocapture maneuver, the guidance system targets a path that culminates in a working orbit with an apogee of $300 \mathrm{~km}$. The atmospheric flight corridor is bounded by a "lift up' trajectory and a 'lift down' trajectory. Figure 3 provides plots that characterize the altitude versus flight vehicle relative speed and the heatshield's stagnation point heat flux versus time for both the lift up and lift down trajectories.

Once the flight vehicle exits the atmosphere, the aerocapture maneuver will have allowed the flight vehicle to shed over $95 \%$ of the $\Delta V$ required to attain the final working orbit, corresponding to a value of $\Delta V=2 \mathrm{~km} / \mathrm{s}$. The second TCM is a short burn that executes at the $300 \mathrm{~km}$ apoapsis point, raising the periapsis to over $130 \mathrm{~km}$ such that a stable parking orbit is attained. Over the next two orbits, the flight vehicle telemeters multiple replays of all accumulated experiment data to the ground system. After all data is downlinked, the third and final TCM executes to deorbit the flight vehicle and dispose of it safely in the Pacific Ocean. The total flight time of the entire mission
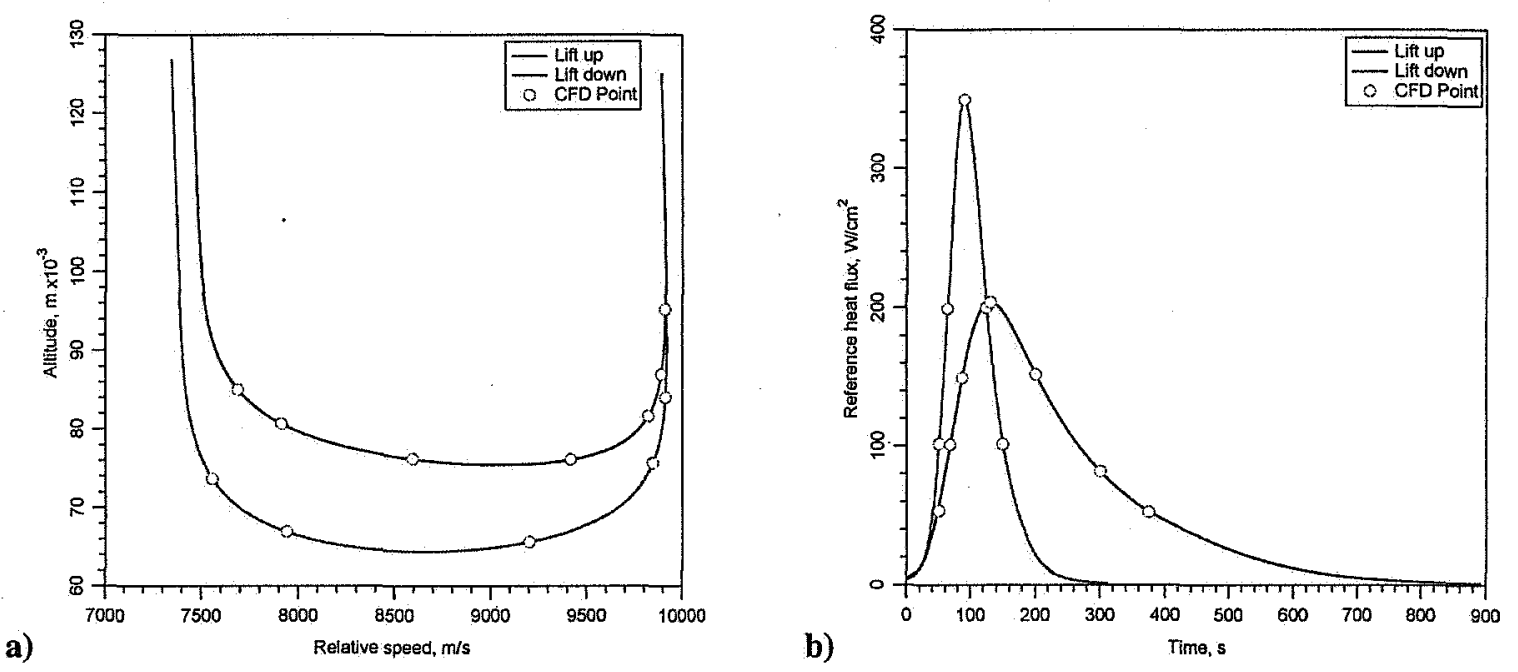

Figure 3. Predicted environmental parameters stated in terms of (a) altitude vs. relative speed and (b) heat flux experienced at the heatshield stagnation point vs. time. Both plots contrast the "lift up" trajectory corridor limit (red) and the "lift down" trajectory corridor limit (blue). Also shown are points (open circles) chosen for CFD point simulations of aerothermal environments.

from launch until deorbit will nominally be 12.5 hours.

\section{B. Spacecraft Design}

The proposed aerocapture flight validation will employ a three axis controlled entry flight vehicle comprising a blunt-body heritage aeroshell geometry. The blunt-body design is uncomplicated, stable upon atmospheric entry, and possess a high level of heritage among successful re-entry vehicles used on previous missions such as the Mars Pathfinder ${ }^{7}$, Genesis ${ }^{8}$, and Stardust ${ }^{9,10}$ flight vehicles. Of importance to the hypersonic navigation during the aerocapture maneuver, the blunt-body shape provides a low lift-to-drag ratio of 0.2 . The flight vehicle's center-ofmass placement determines the attitude trim attained during the aerocapture maneuver, with the aerodynamic lift controlled by the flight vehicle's angle of attack, which is in turn modified during flight by the vehicle's attitude control thrusters.

Figure 4 provides an external view of the flight vehicle shape and appearance. The outer spacecraft structure comprises a forebody heatshield attached to a truncated conical aftbody backshell. Located interior to the spacecraft is a central deck for mounting all internal spacecraft components. A circular close-out panel caps the aftbody backshell and is used for mounting external equipment such as antennas, radiators, and access panels. The close-out 


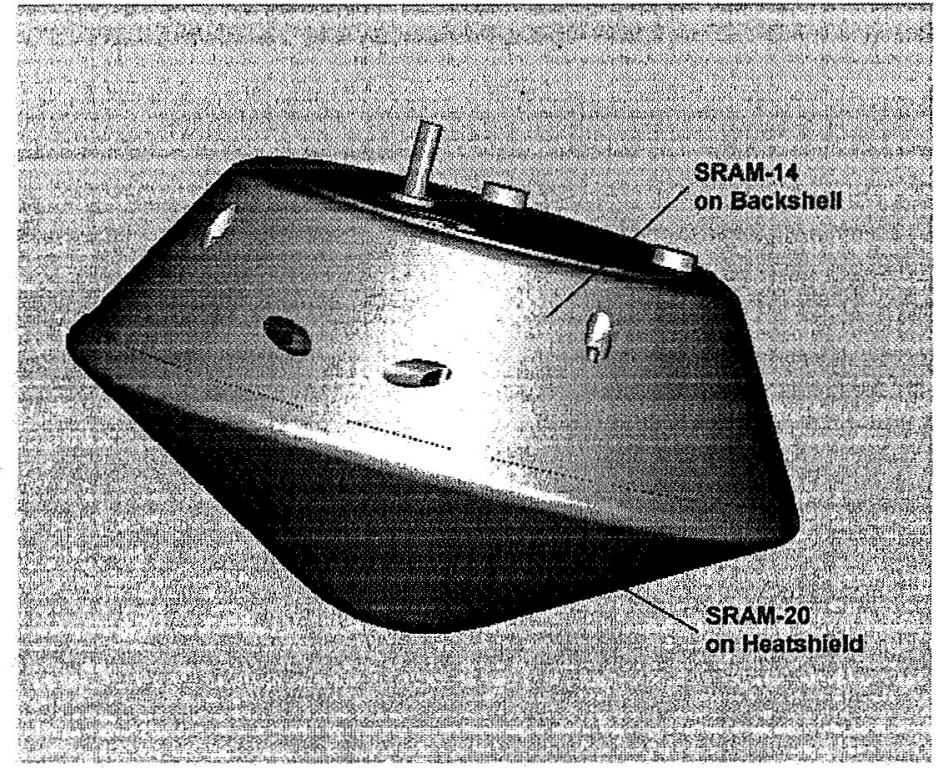

Figure 4. Exterior view of the ST9 Aerocapture flight vehicle with SRAM-20 protecting the heatshield and SRAM-14 protecting the backshell.

panel also serves as the mounting location for the launch vehicle adapter plate. During - launch, all loads are transferred from the launch vehicle, through the attached launch vehicle adapter, through the aeroshells close-out panel, through the aftbody backshell, and onto the fittings that support the central equipment deck and forebody heatshield. This load train must support axial accelerations of up to $16 \mathrm{~g}$ and possess an axial vibrational mode greater than 35 $\mathrm{Hz}$. Likewise, the load train must additionally support lateral accelerations of up to $6 \mathrm{~g}$ and possess a lateral vibrational mode greater than $15 \mathrm{~Hz}$. The forebody heatshield is structurally designed to be sufficiently stiff such that the required shape for proper aerodynamic performance is maintained throughout the aerocapture maneuver. CFD assessments of the aerodynamic environment show the maximum pressure encountered at the heatshield's stagnation point is $8.0 \mathrm{kPa}$, with an average pressure of $5.0 \mathrm{kPa}$ over the surface area of the heatshield. This equates

to a force of $6.8 \mathrm{kN}$ distributed over the surface area of the heatshield. Structural performance of the aeroshell is verified through the use of finite element analysis techniques.

An aluminum honeycomb structural mesh forms the shapes of the forebody heatshield, the aftbody backshell, and the central deck that hosts the flight vehicle's internal components. For use as the heatshield and backshell, this honeycomb mesh is bonded to an outer and inner skin. Together, they make a layered sandwich structure that possesses structural strength and thermal insulative properties. The skin of the sandwich structure consists of a standard modulus carbon fiber woven into a plain weave form and impregnated with a high temperature Polycyanate resin. The thickness of this skin-like facesheet is selectively thicker in regions of the heatshield and backshell that require greater stiffness to endure launch loading and structural integrity under aerodynamic pressures. The central deck provides a mounting plate for all internal components of the flight vehicle. Like the heatshield and backshell, it is also of a sandwich panel construction, but instead of the woven carbon fiber skins, has upper and lower skins of aluminum face sheeting. The central deck is mounted to the aeroshell aft body structure via three fittings located around the circumference of the deck. The fittings are designed to carry the mass of the equipment deck under launch and aerocapture loads while minimizing the impact of thermally induced loads at the interface.

The aft closeout panel is a machined aluminum panel that plays several roles. The first role of this piece of structure is as the primary interface to the launch vehicle adapter. Three separation bolt interfaces are located at the perimeter of the plate, near the interface with the Backshell Interface Ring (BIR). The plate is mounted to the BIR be a circular bolt pattern which is designated to minimize the impact of thermally induced loads at the interface. The second role of the closeout plate is as the primary radiator for thermal management of the spacecraft components mounted to the central deck. The aft closeout plate is thermally coupled to the central deck via a diode heat pipe. The third role of the closeout plate is as the mounting interface for the spacecraft Global Positioning System antennas and S-Band antenna.

\section{Aerocapture Technology Formulation, Development, Validation, and Infusion}

The system-level objectives of the proposed ST9 aerocapture mission are to demonstrate satisfactory performance of the integrated flight vehicle during the aerocapture maneuver and to acquire sufficient experimental data to validate and improve the efficacy of tools used for design, simulation, and modeling. To achieve these objectives, a true in-space validation of the system operating in a relevant environment is required. The proposed aerocapture mission combines a high-fidelity flight vehicle within a relevant flight environment to make for a fair and comprehensive test of aerocapture technology. 
The aerocapture maneuver itself is implemented as an onboard feedback control system that steers a flight vehicle through the atmosphere and delivers it into a precise orbit. The key elements of this control system are:

- Aerodynamic lift that allows for mass efficient trajectory modulation in the atmosphere,

- Attitude control thusters to change the orientation of the spacecraft and its attendant lift vector,

- An inertial measurement unit (IMU) to provide the vehicle state during the maneuver,

- Control software that executes a guidance algorithm based on IMU inputs and lift vector orientation outputs, and

- An aeroshell around the spacecraft that simultaneously maintains a proper outer envelope shape for the provision of aerodynamic forces (lift and drag) and protects the spacecraft from severe heating loads experienced during hypersonic flight.

Most of these elements are readily available today and already have some level of verified flight heritage. The exceptions are the control software that executes the guidance system needed to perform the maneuver and the thermal protection system that protects the spacecraft from severe heating loads. These two advanced technologies are being forwarded in this proposal as technologies requiring flight validation for infusion into future missions.

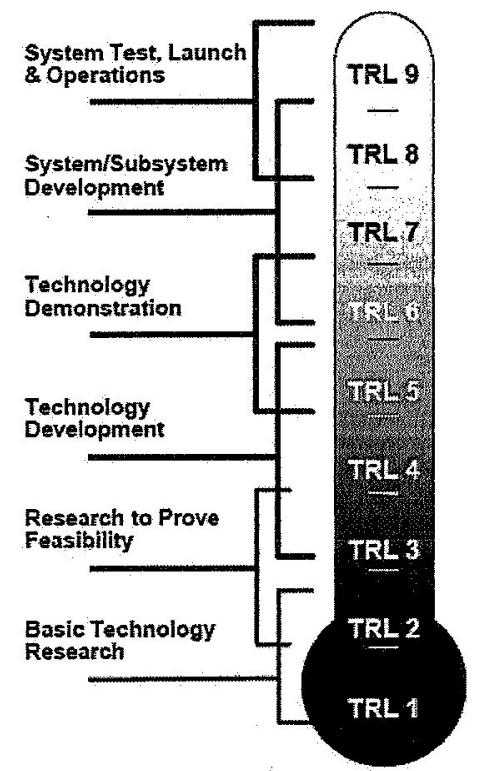

Actual system "flight proven" through successful mission operations

Actual system completed and "flight qualified" through test and demonstration (Ground or Flight)

System prototype demonstration in a space environment

System/subsystem model or prototype demonstration in a relevant environment (Ground or Space)

Component and/or breadboard validation in relevant environment

Component and/or breadboard validation in laboratory environment

Analytical and experimental critical function and/or characteristic proof-of-concept

Technology concept and/or application formulated

Basic principles observed and reported

Figure 5. Technology Readiness Level Definitions.

To ensure any new advanced technology being proposed for a first time flight is sufficiently mature, the NMP employs a technology rating standard, known to NASA technologists as the Technology Readiness Level (TRL) scale, to assist with the assessment of a technology's maturation and test. Figure 5 shows the standard definitions NASA uses to rate a technology's TRL. By meeting the requirements of each level within the TRL scale, a technology advances in rank and maturity until it is ready for flight. The NMP requires any advanced technology that is proposed for flight to have attained at least the TRL 4 rating prior to the submittal of the CDSR, the TRL 5 level prior to the projects Critical Design Review (CDR) and the TRL 6 level prior to flight. The following subsections discuss the advanced technologies proposed for the ST9 aerocapture mission and their TRL ratings.

\section{A. Guidance Navigation \& Control}

The aerocapture guidance, navigation, and control (GN\&C) algorithm, provided by Ball Aerospace and Technologies Corporation, precisely targets the aerocapture flight vehicle prior to its entry into a planetary atmosphere and then autonomously guides the vehicle's atmospheric entry, its hypersonic glide and maneuvering, and its return to space. The guidance algorithm is highly configurable and adaptable to a wide range of initial state vectors, vehicle lift-to-drag ratios, ballistic coefficients, planetary atmospheres, and target orbits through the initialization of a small set of constants. The algorithm, by design, uses a sequence of non-iterative, non-recursive calculations, resulting in a very efficient, predictable, and consistent execution time. The algorithm's performance and robustness have been demonstrated using validated Monte Carlo trajectory simulation tools for a variety of aerocapture mission concepts at Earth, Mars, Titan, and Neptune. These Monte Carlo simulations include 
atmosphere density profile variations, random density perturbations, variations in entry conditions, variations in aerodynamic parameters, and navigation errors. Through the combination of these features, the guidance algorithm provides a low-risk, high performance solution not only for the proposed ST9 aerocapture flight experiment, but for future space science and exploration missions as well.

Inputs to the GN\&C algorithm include the current vehicle position vector, velocity vector, sensed acceleration vector, and vehicle attitude obtained from the on-board navigation system. Outputs from the algorithm include a desired bank angle and a rotational direction toward the desired bank angle. These outputs are subsequently executed by the vehicle's attitude control system. A positive angle-of-attack provides the vehicle with a 'ift-up' change in attitude and a negative angle of attack provides the vehicle with a 'lift-down' change in attitude. A general depiction of the relationship between angle-of-attack, velocity vector, and other pertinent navigational vectors is depicted in Fig.6.

The ST9 GN\&C algorithm originates in the software developed for the Aeroassist Flight Experiment (AFE) program $^{11}$. Beneficial developments to the algorithm come from the large base of aerocapture guidance algorithm work that was completed in support of NASA's AFE program, aerocapture for NASA's Mars Surveyor Program, and the joint effort between NASA and France's Centre National d'Études Spatiales aimed at developing aerocapture guidance for the Mars Sample Return and the Mars Premier missions. Further refinement of the algorithm occurred in response to the aerocapture system analysis studies for various flight vehicle designs, various target orbits, and various destinations. Investments over the past few years by NASA's ISPT project for aerocapture systems studies have also contributed to the development of the algorithm. Through evaluation of guidance performance under a variety of conditions, the algorithm is now mature, robust, and generically applicable to multiple Solar System destinations. The generic nature of the algorithm is attributable to the critical features incorporated into the algorithm, including:

- A nonbiased, independent operation regardless of flight vehicle size, lift-to-drag ratio, and ballistic coefficient,

- Applicability to all destinations in our Solar System with appreciable atmospheres,

- Automatic compensation during flight for large uncertainties and variations in the atmosphere density profile as well as random density perturbations,

- Automatic compensation for variation in vehicle aerodynamic parameters during flight,

- Ability to capture nearly 100 percent of the theoretical entry corridor (providing robustness to entry target delivery errors), and

- Tolerance to navigation system errors during aerocapture flight.

Although guided hypersonic flight has been performed successfully many times, demonstration of a controlled atmospheric exit required for an aerocapture maneuver has never been accomplished in flight. The atmospheric exit phase poses unique challenges to the flight vehicle that are not encountered in any other flight regime. As the flight vehicle leaves the atmosphere, the flight corridor continues to narrow, the vehicle's altitude continues to increase, and the dynamic pressure continues to decrease, resulting in a rapid and significant decrease in the vehicle's control authority and lift capability. The ST9 algorithm has several built-in features to maximize robustness to dispersions during this critical exit phase of flight. First, the "on-the-fly" estimation of atmospheric density and atmospheric scale height minimizes sensitivity to absolute atmosphere density uncertainty and random perturbations. Second, the innovative method used to incorporate deceleration due to drag feedback in the exit phase of flight makes the algorithm tolerant of navigation system errors since it does not have to rely on altitude rate information alone to guide the vehicle out of the atmosphere. Third, the use of deceleration due to drag and altitude rate feedback in the equilibrium glide phase ensures that the vehicle makes significant trajectory corrections during the high dynamic pressure portion of the flight where control authority is high, thus reserving more bank angle capability to handle dispersions during the exit phase of flight. Finally, for extremely demanding future missions, the algorithm is easily extended to provide angle of attack modulation that further increases its capability to handle large density dispersions and uncertainties. Therefore, validating the guidance algorithm through the ST9 flight experiment will provide a robust solution to the issues involved with the critical exit phase of aerocapture flight. 
To comply with NMP requirements for proposing only sufficiently advanced technologies, it is imperative to clearly define the maturity objectives for the aerocapture guidance algorithm and software. A complete prototype implementation of the guidance algorithm, tested in 4-degrees-of-freedom (DOF) Monte Carlo trajectory simulations for several different sets of mission and vehicle design parameters, produced results that comply with the greater than 3-sigma capture rates and targeting performance metrics. This process of exercising the guidance software complies with the approved maturity level of TRL 4, the level required for CDSR proposal submittal.

Through work completed during the formulation of the ST9 aerocapture mission, the TRL 4 prototype code was translated into $\mathrm{C}$ code, integrated into a 6-DOF simulation with other GN\&C algorithms in the loop, and completed Monte Carlo simulations for the specific ST9 aerocapture mission. The results show that the algorithm meets all performance metrics in this testing environment. Based on the results of previous work and that completed during the concept definition study, the guidance algorithm is currently rated at TRL 5 .

\section{B. Thermal Protection System}

The TPS materials selected to protect the flight vehicle during the aerocapture maneuver are SRAM-20 and SRAM-14. These materials, developed by the Ablatives Laboratory of Applied Research Associates (ARA), demonstrate high potential for thermal protection of not only the ST9 flight vehicle, but also any number of proposed NASA entry vehicles for missions to Mars, Venus, Titan, and Earth return. The SRAM family of TPS materials are silicone ablators. The material family possesses qualities of lightweight mass, low thermal conductivity, intrinsic oxidation resistance, and relatively uncomplicated manufacturing. Key materials have densities ranging from $0.22 \mathrm{~g} / \mathrm{cm}^{3}$ to $0.38 \mathrm{~g} / \mathrm{cm}^{3}$. Considering the harsh environment encountered by the flight vehicle's heatshield, SRAM-20 was selected as the forebody acreage TPS material because it possesses the proper balance of mass and performance for the predicted ST-9 heating environment. SRAM-20 has high efficiency for peak heating up to $300 \mathrm{~W} / \mathrm{cm}^{2}$ and can accommodate short term exposures up to $400 \mathrm{~W} / \mathrm{cm}^{2}$. SRAM-20's thermalablation response model includes in-depth pyrolysis, transpiration cooling, and thermochemical surface recession. This model provides an accurate match to ground test results as performed in the arc jet environmental simulation facility of NASA's Ames Research Center (ARC). SRAM-20 is an excellent choice for many new missions and herein rests the impetus for flight validation on the proposed ST-9 flight.

In contrast to the harsh environmental heat loads and pressures experienced by the flight vehicle's heatshield, the backshell will be in the flight vehicle's wake and will thus experience a more benign environment. However, the backshell still requires a TPS to thermally protect the flight vehicle. In keeping with the reasoning of flight validating an advanced material from the SRAM family for purposes of infusing the new flight validated technology into future NASA missions, another member of the same SRAM family, SRAM-14, was selected to cover the aftbody backshell. SRAM-14 is much like its sister material SRAM-20 in that is also a lightweight silicone ablator, but is slightly different in composition; making it lighter in weight and less tolerant of high heat loads. Like SRAM20, SRAM-14 is also undergoing environmental testing in NASA's arc jet facilities as a part of the studies being conducted in support of the ST9 aerocapture CDSR proposal.

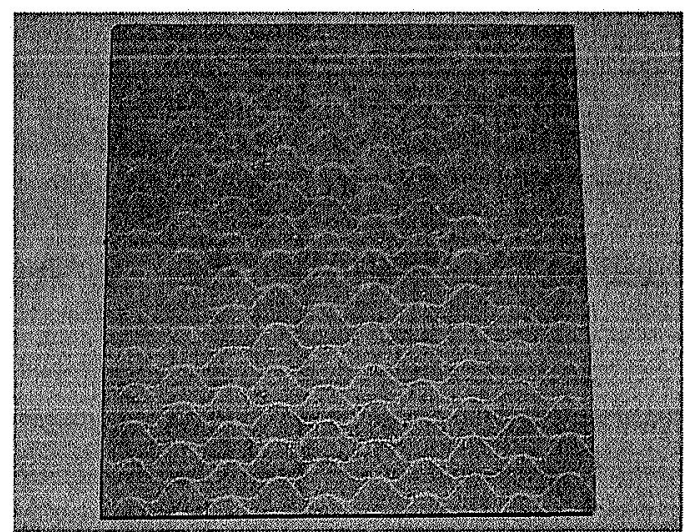

Figure 7. Section of cured ablator panel in large-cell honeycomb.

SRAM test articles and panels are produced at ARA though a large-cell honeycomb structure packing technique. The honeycomb structure possesses a flexible cell geometry, sometimes known as "flex core," that allows the sheets to bend in two directions and conform to the three-dimensional sphere-cone shapes encountered along the surface envelopes of the aeroshell heatshields. The cell size proposed for the flight vehicle is approximately $2.5 \mathrm{~cm}$ and the area of each cell is roughly equivalent to a standard postage stamp.

The SRAM will be applied to the proposed ST9 flight vehicle by first bonding the honeycomb sheet to the facesheet of the heatshield structure. Then, the honeycomb cells are packed with the SRAM ablator compound. Curing is accomplished by vacuum bag pressure and elevated temperature. The primary purpose of honeycomb structure is to stabilize the char layer during entry and prevent mechanical separation and loss of char from the surface. Char

loss would produce a rough surface region and cause interference heating in addition to loss of thermal insulation material. However, honeycomb serves other functions besides char stabilization. In some applications it is commonly used to control ablator thickness during manufacture. In this case, the honeycomb sheet is made to design 
thickness with required tolerance, then the cured, overpacked ablator is milled down to the top of the honeycomb sheet. SRAM-20 uses honeycomb for enhancement of char stability but, if needed, could also use its pre-milled honeycomb thickness to control ablator thickness during manufacture. For the ST-9 aerocapture vehicle, SRAM-20 ablator thickness will be strictly controlled by solid-model driven precision machining of the packed and cured ablator already firmly bonded on the vehicle's structure.

Arc-jet testing characterizes and verifies heatshield performance against flight environments, but it is also critical for assuring an accurate thermal-ablation response model for the SRAM-20 ablator to enable reliable flight predictions. An accurate, reliable thermal model is a critical component of heatshield engineering for NASA spacecraft systems. And one of the most important aspects of flight validating a new ablator such as SRAM-20 on the ST-9 aerocapture mission is that it provides for the flight validation of the ablator's response model. Flight data from the sensors embedded within the TPS materials will be compared to flight predictions to assess whether the thermal model is accurate and conservative. Positive agreement will validate the model and provide confidence that model predictions for other, future missions well founded.

\section{Sensors}

To properly validate the performance of the guidance system and its ability to use aerodynamic forces to modulate the flight vehicle's trajectory, the aerodynamic environment through which the flight vehicle navigates must be fully understood. By verifying aerodynamic models against the guidance system's response to an aerocapture maneuver within Earth's atmosphere, the ability to accurately predict the system's response to a different planetary atmosphere increases by virtue of improved aerodynamic models. Key to verifying the guidance system's response and the performance of the TPS materials in flight is the use of instrumentation as strategically positioned about the flight vehicle.

The ST-9 aerocapture validation experiment is unique among atmospheric entry vehicles in that, if selected, it

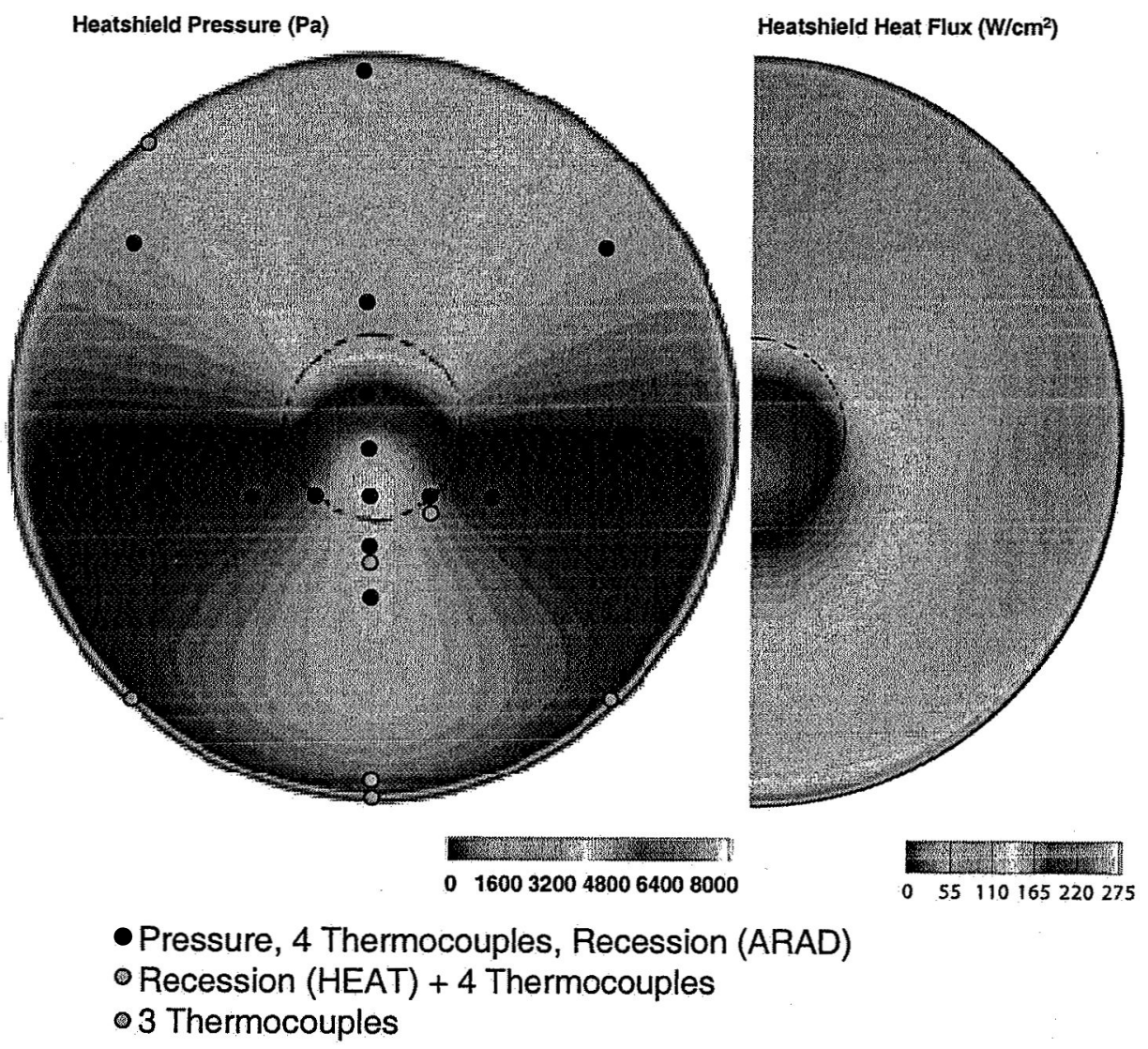

Figure 8. Depicts the locations of the yarious sensors as located within the heatshield. 


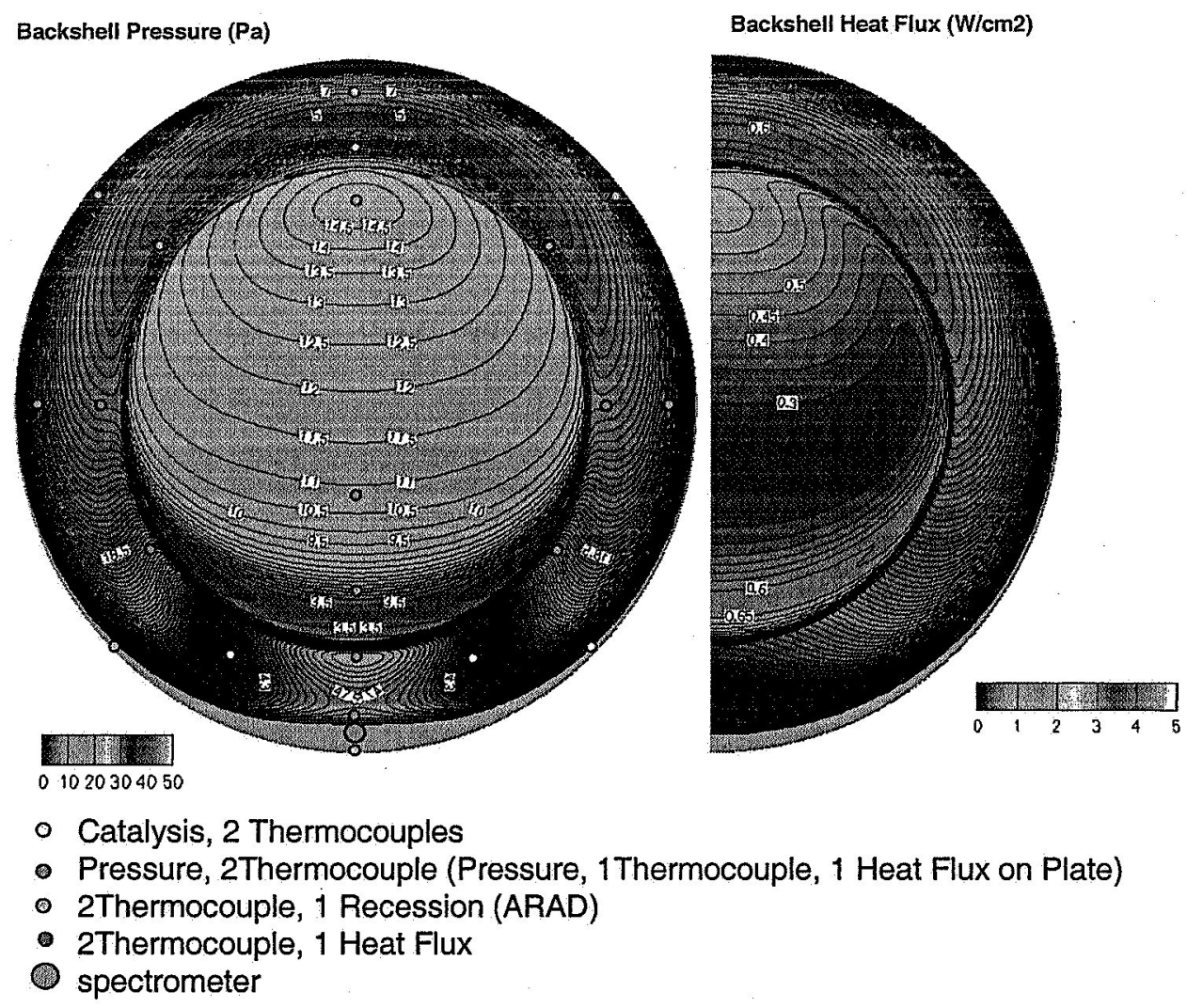

Figure 9. Depicts the locations of the various sensors as located within the backshell.

will be the most heavily instrumented atmospheric re-entry vehicle ever flown. The flight vehicle will use a vehicle state, flowfield and heatshield response instrumentation system based on a mix of TRL 9 components and TRL 6-7 advanced sensor components. This system will consist of an IMU, a series of pressure ports in the forebody of the vehicle in the configuration of a Flush Air Data System, aftbody pressure sensors, embedded thermocouples, material recession sensors, and heat flux gauges. An optical spectrometer is also baselined to provide verification of the relative amounts of chemical constituents encountered in the shock layer.

Figure 8 depicts the locations and types of sensors planned for inclusion on the flight vehicle's forebody heatshield and Fig. 9 depicts the locations and types of sensors planned for inclusion on the flight vehicle's aftbody backshell. These sensors are specifically positioned to measure temperatures, pressures, and recession rates of the TPS material at various locations on the forebody heatshield and aftbody backshell. The data collected by the sensor suite will be used to validate ground-based model predictions and the performance of the guidance system.

\section{Conclusion}

This overview of the proposed ST9 aerocapture flight opportunity establishes the value of a flight demonstration of the aerocapture maneuver. Once validated, the aerocapture maneuver will provide a valuable method for delivering payload mass into orbit around Solar System destinations possessing an appreciable atmosphere. The use of the atmosphere to reduce the transit velocity by a specific $\Delta V$ rather than the expenditure of propellant allows a distinct mass advantage-in some cases to the degree that the maneuver is an enabling capability for tight working orbits around certain gas giant destinations such as Saturn and Jupiter. The proposed flight experiment comprises a low complexity, short duration mission and is designed such that a successful flight of the aerocapture maneuver will be sufficient for immediate infusion of the aerocapture system-level technologies into planned NASA science missions to small planets. Of particular importance to the mission is the flight verification of two advanced technologies requiring flight validation; namely an advanced guidance, navigation and control system and an advanced TPS that uses the advanced SRAM-20 TPS material to thermally protect the forebody heatshield and the advanced SRAM-14 TPS material to protect the aftbody backshell. Sensors are also added to the flight vehicle to accumulate the data necessary to characterize the thermodynamic environment being traversed by the flight vehicle during the aerocapture maneuver. This acquired data will be used to verify the predictions and performance of codes 
used to determine environmental conditions for not only Earth's atmosphere but also the atmospheres of the perspective targets for future aerocapture maneuver implementation.

\section{Acknowledgements}

The authors of this overview wish to acknowledge the efforts and contributions of the ST9 Aerocapture proposal team as located at the NASA field centers of JPL, Ames Research Center, Marshall Space Flight Center, Langley Research Center, and contractors ARA Ablatives Laboratory and Ball Aerospace.

The work described in this paper was funded in whole or in part by the In-Space Propulsion Technology Program, which is managed by NASA's Science Mission Directorate in Washington, D.C., and implemented by the In-Space Propulsion Technology Project at Marshall Space Flight Center in Huntsville, Ala. The program objective is to develop in-space propulsion technologies that can enable or benefit near and mid-term NASA space science missions by significantly reducing cost, mass or travel times.

\section{References}

${ }^{1}$ Hall, J. L., Noca, M. A., and Bailey, R. W., "Cost-Benefit Analysis of the Aerocapture Mission Set," Journal of Spacecraft and Rockets, Vol. 42, No. 2, March-April, 2005.

${ }^{2}$ Hall, J. L., "An Overview of the Aerocapture Flight Test Experiment (AFTE)," ALAA Atmospheric Flight Mechanics Conference and Exhibit, AIAA Paper 2002-4621, 2002.

${ }^{3}$ James, B., Munk, M., and Moon, S., "Aerocapture Technology Project Overview," $39^{\text {th }}$ Joint Propulsion Conference and Exhibit, AIAA Paper 2003-4654, 2003.

${ }^{4}$ Lockwood, M. K., et al., "Aerocapture Systems Analysis for a Titan Mission," NASA TM-2006-214273, URL: http://hdl.handle.net/2002/16166, 2006.

${ }^{5}$ Lockwood, M. K., et al., "Systems Analysis for a Venus Aerocapture Mission," NASA-2006-214291, URL: http:/hdl.handle.net/2002/16212, 2006.

${ }^{6}$ Lockwood, M. K., et al., "Aerocapture Systems Analysis for a Neptune Mission," NASA TM-2006-214300, URL: http://hdl.handle.net/2002/16221, 2006.

${ }^{7}$ Willcockson, W. H., "Mars Pathfinder Heatshield Design and Flight Experience," Journal of Spacecraft and Rockets, Vol. 36, No. 3, May-June, 1999.

${ }^{8}$ Desai, P. N. and Cheatwood, F. M., "Entry Dispersion Analysis for the Genesis Sample Return Capsule," Journal of Spacecraft and Rockets, Vol. 38, No. 3, May-June, 2001.

${ }^{9}$ Willcockson, W. H., "Stardust Sample Return Capsule Design Experience," Journal of Spacecraft and Rockets, Vol. 36, No. 3, May-June, 1999.

${ }^{10}$ Desai, P. N. and Cheatwood, F. M., "Entry Dispersion Analysis for the Stardust Comet Sample Return Capsule," Journal of Spacecraft and Rockets, Vol. 36, No. 3, May-June, 1999.

${ }^{11}$ Williams, L. J., Putnam, T. W., and Morris, R., "Aeroassist Key Returning from Space and the Case for AFE," NASA TM110479, URL: http://hdl.handle.net/2060/19960054409, 1994. 